\title{
SUPPRESSION OF ADVERSE ANGIOGENESIS IN AN ALBUMIN-BASED HYDROGEL FOR ARTICULAR CARTILAGE AND INTERVERTEBRAL DISC REGENERATION
}

\author{
B. Scholz ${ }^{1}$, C. Kinzelmann ${ }^{1}$, K. Benz ${ }^{1}$, J. Mollenhauer ${ }^{1,2}$, H. Wurst ${ }^{1}$, and B. Schlosshauer ${ }^{1, *}$ \\ ${ }^{1}$ NMI Natural and Medical Sciences Institute at the University of Tubingen, Reutlingen, Germany \\ ${ }^{2}$ TETEC Tissue Engineering Technologies AG, Reutlingen, Germany
}

\begin{abstract}
An injectable polyethylene glycol-crosslinked albumin gel (AG) supplemented with hyaluronic acid as a matrix for autologous chondrocyte implantation was evaluated with regard to its impact on angiogenesis. Healthy articular cartilage and intervertebral discs (IVD) are devoid of blood vessels, whereas pathological blood vessel formation augments degeneration of both theses tissues. In contrast to human endothelial cells, primary human articular chondrocytes encapsulated in the AG retained their viability. Endothelial cells did not adhere to the gel surface to a significant extent nor did they proliferate in vitro. The AG did not release any diffusible toxic components. Contrary to Matrigel ${ }^{\mathrm{TM}}$ employed as positive control, the AG prevented endothelial chemoinvasion in Transwell filter assays even in the presence of a chemotactic gradient of vascular endothelial growth factor. In ovo, the AG exhibited a barrier function for blood vessels of the chick chorioallantoic membrane. Subcutaneous implantation of human IVD chondrocytes enclosed in the albumin gel into immunodeficient mice revealed a complete lack of angiogenesis inside the gel after two weeks. At the same time, the IVD chondrocytes within the gel remained vital and displayed a characteristic gene expression pattern as judged from aggrecan, collagen type I and type II mRNA levels. In summary, aiming at articular cartilage and IVD regeneration the albumin gel promises to be a beneficial implant matrix for chondrocytes simultaneously exhibiting non-permissive properties for adverse endothelial cells.
\end{abstract}

Keywords: Angiogenesis, articular cartilage, injectable hydrogel, intervertebral disc, regeneration.

\footnotetext{
*Address for correspondence:

Burkhard Schlosshauer

NMI Natural and Medical Sciences Institute at the University of Tubingen,

Markwiesenstrasse 55

D-72770 Reutlingen, Germany

Telephone Number: +49 7121 51530-20

FAX Number: +49 7121 51530-16

E-mail: schlosshauer@nmi.de
}

\section{Introduction}

Articular cartilage defects or intervertebral disc (IVD) degeneration call for an efficient early-onset long-term therapy to postpone or prevent radical surgical interventions such as total joint replacement or spinal fusion. The implantation of autologous articular chondrocytes or IVD chondrocytes within a biomaterial into the degenerated tissue is thought to overcome the reduced self-regeneration capacity (Hunziker, 1999; Roughley, 2004; Vinatier et al., 2009) of these tissues at least partially (Hunziker, 1999; Paesold et al., 2007).

The choice of an ideal biomaterial is crucial for successful regeneration. In general, a biomaterial should mimic the microenvironment of the desired tissue (Anderson et al., 2005). As reviewed by Chan and Leong (2008), biomaterials should furthermore be bioactive, cyto- and tissue compatible, should provide mechanical support and void volume for tissue formation and remodelling. For many applications resorption of the biomaterial is advantageous as well. Many biomaterials have been investigated for both autologous chondrocyte implantation and implantation of IVD chondrocytes (Anderson et al., 2005; Vinatier et al., 2009). One obstacle facing pre-made porous scaffolds, which are commonly used for articular cartilage and IVD tissue engineering, is co-morbidity from an occasionally highly invasive implantation procedure (Chan and Leong, 2008). By contrast, injectable hydrogels can be transferred minimally invasive into the defect via a small incision (Boyd and Carter, 2006; Vinatier et al., 2009). The liquid hydrogels can integrate even into an irregularly shaped defect before solidification takes place (Boyd and Carter, 2006). Another advantage of hydrogels is the high water content resembling the conditions in native cartilage (Sontjens et al., 2006). Besides these biological reflections, a rapid approval for clinical application is desirable. Medical prescription formulations of human serum albumin have already drug status illustrating one main rationale for the choice of albumin as major gel component in our hydrogel.

A special feature of healthy mature articular cartilage and the IVD is the absence of blood vessels. However, blood vessels may appear during pathophysiological conditions (Ballara et al., 1999; Huber et al., 2000) - a fact, which we propose should be considered when designing an optimized biomaterial for articular cartilage and IVD regeneration.

Inflammation and angiogenesis are processes being involved in the progression of osteoarthritis (OA) (Ballara et al., 1999). In joints of OA-patients, the inflammatory cytokine interleukin-1 (IL-1) not only induces the expression of matrix metalloproteinases (MMPs), which 
are responsible for cartilage matrix degradation, but also stimulates chondrocytes to express vascular endothelial growth factor (VEGF). This pro-angiogenic growth factor leads to the penetration of blood vessels originating from the subchondral bone into the cartilage (Bonnet and Walsh, 2005) which causes the subsequent ingrowth of bony outgrowths (Ballara et al., 1999) and nerve supply by sensory neurons representing a major cause for pain (Ashraf and Walsh, 2008).

As described for articular cartilage, innervation of the IVD accompanied by pain is probably also dependent on angiogenesis (Johnson et al., 2001; Paesold et al., 2007) and angiogenesis seems to enhance degeneration of the IVD after herniation (Ballara et al., 1999; Haro et al., 2002). In conclusion, angiogenesis also seems to augment IVD degeneration and pain.

We propose a biomaterial which inhibits the ingrowth of blood vessels after autologous chondrocyte implantation as being advantageous for the regeneration of articular cartilage and the IVD. Therefore, we investigated the influence of an injectable hydrogel for articular cartilage and IVD regeneration, which already has obtained a pharmaceutical product license and is currently investigated in a Phase I clinical trial, on blood vessel formation.

\section{Materials and Methods}

\section{Materials}

Penicillin-G and streptomycin were purchased from PAA (Pasching, Austria). 4',6-diamidino-2-phenylindole (DAPI), gelatin, propidium iodide, Rose Bengal dye as well as resazurin were obtained from Sigma-Aldrich (Steinheim, Germany). Vascular endothelial growth factor (VEGF) was from PeproTech (recombinant human VEGF165, Rocky Hill, NJ, USA). Acetylated low-density lipoprotein labelled with 1,1'-dioctadecyl-3,3,3',3'tetramethyl-indocarbocyanine perchlorate (DiI-Ac-LDL, Biomedical Technologies, Stoughton, MA, USA), calcein and Oregon Green ${ }^{\circledR} 488$ phalloidin (Molecular Probes, Eugene, OR, USA) were also used. Matrigel ${ }^{\mathrm{TM}}$ was purchased from Becton Dickinson (Heidelberg, Germany). Haematoxylin, eosin $\mathrm{G}$ and Coomassie ${ }^{\circledR}$ Brilliant Blue were obtained from Merck (Darmstadt, Germany).

\section{Albumin gel}

Activated sheep maleimido-albumin or activated human maleimido-albumin, hyaluronic acid and cell culture medium without supplements and without serum were used as basis for the albumin gel (AG). Cross-linkage was achieved through a specific thio-polyethylene glycol (HSPEG-SH; Rapp Polymere GmbH, Tubingen, Germany) spacer via Michael reaction of a maleimide-group to a SHgroup. (Pending patents number: PCT/EP2008/005643, DPMA 102008008 071.3). Unless otherwise stated, sheep serum albumin was utilized for the experiments.

For the production of maleimido-albumin, $250 \mathrm{mg}$ of human or sheep serum albumin (Sigma-Aldrich) were dissolved in $5 \mathrm{ml} 1 \mathrm{M}$ sodium borate ( $\mathrm{pH} 8.2$, AppliChem, Darmstadt, Germany). Afterwards $75 \mu 1260$ mM 3- maleimidopropionic acid (Sigma-Aldrich) in PBS/ sodium borate $(\mathrm{pH} 8.2 ; 1: 1)$ were added and incubated for $90 \mathrm{~min}$ at room temperature. $106 \mathrm{mg}$ 3-maleimidopropionic acid N-hydroxysuccinimide ester (Obiter Research, UrbanaChampaign, IL, USA) were dissolved in $950 \mu \mathrm{l}$ dimethylformamide (Biosolve, Valkenswaard, Netherlands) and centrifuged in order to pelletize undissolved 3-maleimidopropionic acid Nhydroxysuccinimide ester. $500 \mu$ of the supernatant were added to the albumin solution and incubated for another $60 \mathrm{~min}$ at room temperature. Afterwards $500 \mu 13 \mathrm{M}$ sodium acetate $(\mathrm{pH} 4.7)$ were added. The sample was dialysed against PBS three times on ice for $1 \mathrm{~h}$ each. The dialysed sample was concentrated to $3.5 \mathrm{ml}$ by ultrafiltration (YM3 membrane, Millipore, Billerica, MA, USA). By this protocol a functionalization of 15 to 25 maleimide-groups per albumin was achieved. The sample was sterilized by sterile-filtration and stored at $-80^{\circ} \mathrm{C}$. To prepare $200 \mu \mathrm{l}$ of the AG, $14 \mu \mathrm{l}$ maleimido-albumin $(43 \mathrm{mM}), 106 \mu \mathrm{l}$ cell culture medium and $40 \mu \mathrm{l} \mathrm{high} \mathrm{molecular}$ weight hyaluronic acid $(20 \mathrm{mg} / \mathrm{ml}$, Visiol, TRB Chemedica, Munich, Germany) were mixed and incubated for $5 \mathrm{~min}$ at room temperature. For different approaches gelatin, VEGF or chondrocytes, as specified below, were added to the indicated cell culture medium. Crosslinkage was achieved by addition of $40 \mu \mathrm{l} \mathrm{HS-PEG-SH}(10000 \mathrm{~g} / \mathrm{mol}$, $15 \mathrm{mM}$ SH-groups), revealing a 1:1 ratio of maleimidegroups to SH-groups. For the subcutaneous dorsal injection of the AG into the backs of immunodeficient mice, a dualvolume syringe with a Luer-lock mixing adapter and an 18-gauge needle was used which allowed local polymerization. For all other experiments HS-PEG-SH was added to the other components and immediately mixed by pipetting before polymerization started.

\section{Tissue samples}

Cartilage tissues were obtained from six osteoarthritis (OA) patients undergoing total endoprosthetic knee replacement. The patients were between 46 and 77 years old, five of them were female and one was male. Only tissue portions with minor signs of degeneration were utilized. Cells isolated from such specimens, displayed no qualitative differences in chondrocyte morphology and no dependency in viability with regard to donor age, gender and the disease stage. Disc tissues were harvested from six patients during spinal fusion surgery. Due to this surgery procedure a clear distinction between nucleus pulposus cells and annulus fibrosus cells was not possible, why these cells were collectively termed "IVD chondrocytes". The patients were between 18 and 61 years old, two of them were female and four were male. All human tissues were obtained from the BG Trauma Clinic in Tubingen (Germany). The studies were approved by the local ethics committee and informed consent was obtained from all individuals participating in the study.

\section{Isolation of human articular and intervertebral disc chondrocytes}

Articular cartilage was removed from the tibial plateau and condyles. Tissue samples were washed in phosphate buffered saline (PBS) and minced. Extracellular matrix 
(ECM) was enzymatically degraded overnight by incubation in Dulbecco's modified Eagle's medium (DMEM; Invitrogen, Karlsruhe, Germany) containing 1.5 $\mathrm{mg} / \mathrm{ml}$ collagenase B (Roche, Mannheim, Germany), 0.1 $\mathrm{mg} / \mathrm{ml}$ hyaluronidase (Serva, Heidelberg, Germany) and $5 \%$ fetal calf serum (FCS; Biochrom, Berlin, Germany) at $37^{\circ} \mathrm{C}$. Isolated chondrocytes were filtered through a 100 $\mu \mathrm{m}$ cell strainer. After centrifugation, the cells were resuspended in cell culture medium and plated in $75 \mathrm{~cm}^{2}$ cell culture flasks at an initial density of $5 \times 10^{5}$ cells. Disc tissue samples were washed twice in PBS and then minced. ECM was degraded overnight by incubation in DMEM containing $0.375 \mathrm{mg} / \mathrm{ml}$ collagenase $\mathrm{B}, 0.05 \mathrm{mg} / \mathrm{ml}$ hyaluronidase and 5\% human AB serum (Centre of Clinical Transfusion Medicine, University of Tubingen, Germany) at $37^{\circ} \mathrm{C}$. Further isolation was performed as described for articular chondrocytes.

\section{Cell culture}

Primary human articular chondrocytes were cultured in DMEM: Ham's F-12 (2:1, Biochrom, Berlin, Germany) supplemented with $10 \%$ FCS, $100 \mathrm{U} / \mathrm{ml}$ penicillin-G, 100 $\mu \mathrm{g} / \mathrm{ml}$ streptomycin and $150 \mathrm{nmol} / \mathrm{ml} \mathrm{L-ascorbate-2-}$ phosphate in a humidified atmosphere $\left(95 \%\right.$ air, $\left.5 \% \mathrm{CO}_{2}\right)$ and were used in passage (P) 1 and 2. Primary intervertebral disc (IVD) chondrocytes were cultured in DMEM: Ham's F-12 supplemented with 5\% human AB serum (Centre for Clinical Transfusion Medicine, University of Tubingen, Germany), $100 \mathrm{U} / \mathrm{ml}$ penicillin-G, $100 \mu \mathrm{g} / \mathrm{ml}$ streptomycin and $150 \mathrm{nmol} / \mathrm{ml} \mathrm{L}$-ascorbate-2-phosphate in a humidified atmosphere $\left(95 \%\right.$ air, $\left.5 \% \mathrm{CO}_{2}\right)$ and were used in $\mathrm{P} 1$. Primary human umbilical vein EC (HUVEC) were purchased from PromoCell (Heidelberg, Germany) and cultured in EC growth medium (ECGM) with supplement mix (both PromoCell), $50 \mathrm{U} / \mathrm{ml}$ penicillin-G and $50 \mu \mathrm{g} / \mathrm{ml}$ streptomycin in a humidified atmosphere (95\% air, 5\% $\mathrm{CO}_{2}$ ). EC were used between P3 and P9. To passage EC, the DetachKit 30 (PromoCell) was used according to manufacturer's instructions. For the characterization of articular chondrocytes within the AG, $2 \times 10^{5}$ chondrocytes were embedded in $200 \mu \mathrm{l}$ AG. Before polymerization, the AG was transferred to a 48 well plate and covered with cell culture medium (see Fig. 1A). As control, $1.5 \times 10^{4}$ chondrocytes were cultured in monolayers in a 48 well plate. For the characterization of HUVEC on AG surfaces, 48 well plates were coated with $100 \mu \mathrm{A}$ AG. After polymerization, $1.5 \times 10^{4}$ HUVEC in ECGM plus supplements were seeded on top of the gel (see Fig. 2A). As a control, the same number of cells was cultured in 48 well plates coated with $100 \mu \mathrm{l}$ AG with $0.5 \%$ gelatin (AG + gelatin), $100 \mu 110 \mathrm{mg} / \mathrm{ml}$ Matrigel $^{\mathrm{TM}}$ or in gelatin-coated 48 well plates $(0.5 \%)$. Polymerization of Matrigel ${ }^{\mathrm{TM}}$ was achieved by incubation at $37^{\circ} \mathrm{C}$ for $30 \mathrm{~min}$.

\section{Chondrocyte vitality}

Vitality of chondrocytes was examined by live-dead staining with calcein and propidium iodide after one and five days. The cells were incubated with $1 \mu \mathrm{g} / \mathrm{ml}$ calcein for $30 \mathrm{~min}$ at $37^{\circ} \mathrm{C}$ and $5 \% \mathrm{CO}_{2}$. After $20 \mathrm{~min}, 3.33 \mu \mathrm{g} / \mathrm{ml}$ propidium iodide was added to the cell culture medium. The AGs were subsequently transferred onto glass slides and squeezed with cover slips. Microscopic analysis was carried out taking optical $3 \mu \mathrm{m}$ interval Z-stack slices with an Apotome Axio Imager (Carl Zeiss, Göttingen, Germany). Vital and dead cells within the AG were counted in 3 randomly chosen Z-stacks (50 positions). Cells under control conditions were analyzed using an Axiovert (Carl Zeiss, Oberkochen, Germany) microscope by counting vital and dead cells in three randomly chosen microscopic fields. The results are indicated as percent vital cells. Experiments were performed three times in duplicate.

\section{EC adhesion}

Cell adhesion of HUVEC was investigated after one and five days by fixation of EC with $2.5 \%$ glutaraldehyde for $20 \mathrm{~min}$ and subsequent staining of the actin cytoskeleton with Oregon Green ${ }^{\circledR} 488$ phalloidin. Furthermore, cell nuclei were visualized with DAPI. For immunofluorescence analysis, cells were washed with PBS and examined by fluorescence microscopy (Axiovert, Carl Zeiss). The number of adherent cells was determined by counting cell nuclei in three randomly selected microscopic fields with the ImageJ (http://rsbweb.nih.gov/ij/) software program. Results are indicated as percent seeded cells. Experiments were performed three times in duplicate.

\section{EC functionality and vitality}

Functionality and vitality of HUVEC were determined by the uptake of DiI-Ac-LDL and by staining with calcein and DAPI after one and five days. Cells were incubated with $10 \mu \mathrm{g} / \mathrm{ml}$ DiI-Ac-LDL in ECGM for $4 \mathrm{~h}$ at $37^{\circ} \mathrm{C}$ and $5 \% \mathrm{CO}_{2}$ (Voyta et al., 1984). After 3.5h, $1 \mu \mathrm{g} / \mathrm{ml}$ calcein was added and the cells were incubated for another 30 min. Dead cells were subsequently stained with $5 \mu \mathrm{g} / \mathrm{ml}$ DAPI for $5 \mathrm{~min}$. For immununofluorescence analysis, cells were washed with ECGM and immediately examined by fluorescence microscopy. The percentage of vital cells was determined by counting dead cells in three randomly chosen microscopic fields. These cells were referred to the total number of fixed cells (see above) which was detected under the different culture conditions and at the different time points. Experiments were performed three times in duplicate.

\section{EC proliferation}

Proliferating EC were detected after one day, using a "5bromo-2'-deoxyuridine (BrdU) Cell Labeling and Detection Kit I" purchased from Roche (Mannheim, Germany). The procedure was performed according to manufacturer's recommendations. BrdU-positive and DAPI-stained cell nuclei were counted in three randomly chosen microscopic fields with the ImageJ software program and the results are stated as percent proliferating cells. Experiments were performed three times in duplicate.

\section{Migration and chemoinvasion assay}

Transwell polycarbonate plates with $6.5 \mathrm{~mm}$ diameter tissue culture inserts containing a membrane with $8 \mu \mathrm{m}$ pores (Corning, Wiesbaden, Germany) were coated with $100 \mu \mathrm{AG}, 100 \mu \mathrm{l} \mathrm{AG}+$ gelatin or $100 \mu \mathrm{l} 5 \mathrm{mg} / \mathrm{ml}$ Matrigel $^{\mathrm{TM}}$ (see Fig. 5A). Because Matrigel ${ }^{\mathrm{TM}}$ is highly liquid before solidification, less volume loss was observed 
during pipetting resulting in a slightly increased thickness of Matrigel ${ }^{\mathrm{TM}}$-coating as compared to the more viscous AG-solution. To analyze the migratory potential of the utilized EC in parallel, uncoated transwell inserts were used as control. Bisbenzimide-stained (Hoechst, Frankfurt, Germany) HUVEC ( $3 \times 10^{4}$ cells) were seeded onto the inserts and allowed to settle down for $2 \mathrm{~h}$. Then inserts were transferred into new 24 wells containing $600 \mu \mathrm{l}$ ECGM with or without $40 \mathrm{ng} / \mathrm{ml}$ VEGF. After $24 \mathrm{~h}$ incubation at $37^{\circ} \mathrm{C}$ and $5 \% \mathrm{CO}_{2}$, the top sides of the filters were cleansed with cotton swabs soaked in PBS. The membranes were fixed in 4\% paraformaldehyde (PFA) for $10 \mathrm{~min}$ at room temperature (RT). Afterwards the inserts were rinsed with PBS. For microscopic analysis the inserts were kept in 24 well plates containing PBS. Cell nuclei on the lower side of the membranes were counted in three randomly chosen microscopic fields using ImageJ software. Experiments were performed three times in duplicate and results are indicated as number of cells/filter. Non-stained cells were utilized for qualitative evaluations. After cleansing the upper side of the membrane, the inserts were transferred to $1 \%$ Rose Bengal dye in $30 \%$ ethanol, rinsed with PBS, mounted on glass slides with fluorescence mounting medium (DAKO, DK) and documented with a microscope

\section{VEGF ELISA}

VEGF expression of chondrocytes from six patients suffering OA cultured for five days within the AG was determined using an anti-VEGF Enzyme-linked Immunosorbent Assay (ELISA) purchased from R\&D Systems (VEGF Quantikine System, WiesbadenNordenstadt, Germany). For determination of the total amount of VEGF released into the medium supernatant, the assay was performed according to manufacturer's instructions. Samples were analysed in duplicate. Optical density was measured at $450 \mathrm{~nm}$ using a PHERAstar spectrophotometer (BMG LABTECH GmbH, Offenburg, Germany). Wavelength correction was set to $570 \mathrm{~nm}$.

\section{Cytotoxicity Assay}

The cytotoxic effect of medium, which was incubated with the AG, on HUVEC and articular chondrocytes was determined. $5 \times 10^{4}$ HUVEC were cultured in gelatincoated 96 well plates and $5 \times 10^{4}$ chondrocytes were cultured in uncoated 96 well plates. After $24 \mathrm{~h}$, cell culture medium was replaced by test medium, which was generated by incubation of $200 \mathrm{mg} \mathrm{AG}, \mathrm{AG}+$ gelatin and

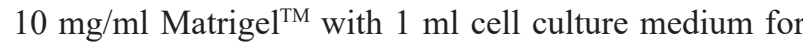
$24 \mathrm{~h}$ at $37^{\circ} \mathrm{C}$ under permanent agitating. Dimethyl sulphoxide (DMSO) served as negative control. Alamar Blue assay was performed after another $24 \mathrm{~h}$. Cells were incubated with $10 \mu \mathrm{g} / \mathrm{ml}$ resazurin for $4 \mathrm{~h}$ (O'Brien et al., 2000). Fluorescence intensity was measured using a Fluostar OPTIMA spectrophotometer (BMG LABTECH, Offenburg, Germany) with excitation and emission set to 570 and $585 \mathrm{~nm}$, respectively. The results are indicated as percent viability relative to the medium-treated control (100\% viability). Experiments were performed six times in triplicate.

\section{Gene expression analysis}

The AG was digested with proteinase $\mathrm{K}(3 \mathrm{mg} / \mathrm{ml})$ for about $10 \mathrm{~min}$ at $37^{\circ} \mathrm{C}$, the digest was centrifuged and the cell pellet was directly lysed in RLT-buffer (Qiagen, Hilden, Germany). Total RNA was extracted using the RNeasy mini kit plus DNase I digestion according to manufacturer's instructions (Qiagen). Complementary DNA (cDNA) was obtained by reverse transcription of 1 $\mu \mathrm{g}$ total RNA using the Reverse Transcriptase Core kit (Eurogentec, Cologne, Germany) with EuroScript reverse transcriptase (Moloney Murine Leukemia Virus reverse transcriptase, $50 \mathrm{U} / \mu \mathrm{l}$ ) and oligo-dT primers. Reverse transcription was performed in a total volume of $50 \mu \mathrm{l}$ at $48^{\circ} \mathrm{C}$ for $30 \mathrm{~min}$ in a thermocycler (Whatman Biometra, Göttingen, Germany). Gene expression was analyzed by quantitative real-time PCR using an Applied Biosystems (Darmstadt, Germany) 7500 Fast Real-Time PCR System. The qPCR mastermix plus SYBR green I (low ROX) kit from Eurogentec was used. To approximately $1 \mathrm{ng}$ of cDNA, $100-300 \mathrm{mM}$ primers (according to the optimal condition for each primer) and the $2 \mathrm{x}$ reaction buffer were added to a total volume of $25 \mu \mathrm{l}$. Primers were designed with the primer express 2.0 software (Applied Biosciences), except primers for collagen type II (Col2A1) (Hengstler et al., 2003), and were obtained from BIOTEZ (Berlin, Germany). Glyceraldehyde-3-phosphate dehydrogenase (GAPDH) was used as housekeeping gene.

\section{Primer sequences:}

\section{GAPDH}

AGAAAAACCTGCCAAATATGATGAC (reverse)

TGGGTGTCGCTGTTGAAGTC (forward)

\section{collagen type I}

GCTGGCAGCCAGTTTGAATATAAT (reverse)

CAGGCGCATGAAGGCAAGT (forward)

\section{collagen type II}

AGAGGTATAATGATAAGGATGTGTGGAAG (reverse)

GTCGTCGCAGAGGACAGTCC (forward)

\section{aggrecan}

TGCATTCCACGAAGCTAACCTT (reverse)

GACGCCTCGCCTTCTTGAA (forward)

The PCR reaction was started with an initial enzyme activation step at $95^{\circ} \mathrm{C}$ for $10 \mathrm{~min}$ (hot start), followed by 40 cycles of $95^{\circ} \mathrm{C}$ for $15 \mathrm{sec}, 60^{\circ} \mathrm{C}$ for $30 \mathrm{sec}$, and $72^{\circ} \mathrm{C}$ for $30 \mathrm{sec}$. A melting curve was generated after the last cycle. Threshold levels (Ct values) were determined using Sequence Detection System software (Applied Biosystems). Ct value of the housekeeping gene was subtracted from the $\mathrm{Ct}$ value of the genes of interest $(\Delta \mathrm{Ct})$ and relative expression depicted as $2^{-\Delta \mathrm{Ct}}$.

\section{Chorioallantoic membrane (CAM) assay}

Fertilized Hisex brown chicken eggs were incubated at $37^{\circ} \mathrm{C}$ and $60 \%$ humidity. After two days of incubation, 2 $\mathrm{ml}$ albumen were aspirated from the eggs. A window was cut into the egg shell and sealed with a Petri dish lid and silicone paste before the eggs were returned to the incubator (Dreesmann et al., 2007). At day eight (Fig. 6A) of incubation, $200 \mu \mathrm{l} \mathrm{AG,} \mathrm{AG} \mathrm{+} \mathrm{gelatin,} \mathrm{AG} \mathrm{+} \mathrm{VEGF} \mathrm{(40} \mathrm{ng/}$ $\mathrm{ml})$ and $\mathrm{AG}+$ articular chondrocytes $\left(2 \times 10^{5}\right.$ cells $)$ were transferred onto the CAM $(n=10)$. As positive control $7 x$ $7.5 \times 1.5 \mathrm{~mm}^{3}$ OptiMaix-3D ${ }^{\mathrm{TM}}$ (Matricel, Herzogenrath, 
Germany) collagen sponges were placed on top of the CAM ( $\mathrm{n}=10)$. After further incubation for five days, the CAMs were collected and fixed in 4\% PFA overnight at $4^{\circ} \mathrm{C}$. Photographs of the CAM were used to determine the orientation of blood vessels in the CAM towards the implant (Fig. 6C). For the negative control, blood vessel orientation was determined towards a randomly chosen circular area (radius $=5 \mathrm{~mm}$ ) of the CAM (without implant). Fixed specimens were dehydrated in $30 \%$ sucrose for at least $48 \mathrm{~h}$, embedded in Tissue Tek (O.C.T. Compound, Sakura, USA) for $24 \mathrm{~h}$ and cryosectioned.

\section{Subcutaneous implantation (NOD/SCID mice)}

All animal experiments were approved by the Committee on Animal Care of the State of Baden-Wurttemberg (Germany). With the aid of a twin-chamber syringe, 1.25 x $10^{6}$ IVD chondrocytes (P 1) enclosed in $250 \mu$ human AG were implanted subcutaneously in the backs of nonobese diabetic/severe combined immune deficiency (NOD/ SCID) mice (Charles River Laboratories, Sulzberg, Germany) (see arrows Fig. 7A). Polymerization was achieved in statu nascendi. Two weeks later, the AG was explanted (Fig. 7A insert), lysed for gene expression analysis $(\mathrm{n}=4)$ or embedded in Tissue Tek, snap-frozen in liquid nitrogen and cryosectioned. As control for gene expression analysis, IVD cells were cultured in monolayers for two weeks $(n=4)$.

\section{Histochemistry}

9 and $14 \mu \mathrm{m}$ cryo sections were stained with haematoxylin and eosin $\mathrm{G}$ according to standard protocols. Microscopic analysis was performed using an Axiophot microscope (Carl Zeiss, Oberkochen, Germany). $7 \mu \mathrm{m}$ cryo sections were permeabilized with $0.2 \%$ Triton X-100 for $10 \mathrm{~min}$, blocked with $1 \%$ BSA for 30 min and stained with FITClabelled Sambucus nigra agglutinin (SNA, Linaris, Wertheim, Germany) for $1 \mathrm{~h}$ at RT. Cell nuclei were visualized with DAPI. Immunofluorescence was analyzed and photographed using an Axiovert microscope.

\section{Immunohistochemistry}

$14 \mu \mathrm{m}$ cryo sections were permeabilized with $0.2 \%$ Triton $\mathrm{X}-100$, blocked with $1 \% \mathrm{BSA} / 5 \%$ serum and incubated with a 1:100 dilution of rabbit anti-von Willebrand factor (vWF) primary antibody (Santa Cruz, Heidelberg, Germany) for $1 \mathrm{~h}$ at RT. For aggrecan staining $30 \mu \mathrm{m}$ sections were not permeabilized, blocked with 3\% BSA for $30 \mathrm{~min}$ and incubated with a 1:40 dilution of mouse anti-aggrecan primary antibody (Acris, Heidelberg, Germany) for $1.5 \mathrm{~h}$ at RT. Incubation with secondary antibody (1:300, goat anti-rabbit, AlexaFluor@488-labeled, Invitrogen, Karlsruhe, Germany; 1:100, goat anti-mouse, Cy3-labeled, Dianova, Hamburg, Germany) was carried out for $1 \mathrm{~h}$ at RT in the dark. Cell nuclei were visualized with DAPI and immunofluorescence analyzed using an Axiovert microscope.

\section{Statistics}

Results are indicated as means \pm standard error. Statistical analysis was performed using StatView (SAS Institute Inc., Cary, NC, USA). One-way ANOVA followed by Fisher-
PLSD post-hoc analysis was used to determine statistical significance. $*$ indicates significance with $p<0.05$, ** indicates significance with $p<0,005$, and $* * *$ indicates significance with $p<0,001$.

\section{Results}

\section{Characterization of chondrocytes within the AG}

Live-dead staining was performed to evaluate articular chondrocyte vitality within the AG. When cultured in monolayers, the chondrocytes adhered to the bottom of the well plate and displayed a fibroblast-like appearance (Fig. 1B and C). However, when cultured within the AG, the cells showed a round morphology with few cell-cell contacts (Fig 1D and E). Chondrocytes were distributed in the AG homogeneously, cluster formation of several cells was only rarely observed. $93 \%$ of the chondrocytes were vital in monolayers after one and five days of culturing and within the AG after one day, while the relative number of vital cells decreased to $80 \%$ after five days within the AG (Fig. 1F). To rule out cytotoxic effects, chondrocytes were incubated with medium supernatants of the AG for one day. In contrast to treatment with DMSO used as negative control, the AG showed no cytotoxic effect on the chondrocytes (Fig. 1G).

\section{Characterization of endothelial cells on AG surfaces}

The impact of the AG on EC was investigated by culturing EC on top of the AG to analyze cell adhesion, vitality, functionality and proliferation. After one and five days of culture, EC stained with phalloidin displayed the typical cobblestone-morphology on 2D-gelatin-coating (Fig. 2C and D). On Matrigel ${ }^{\mathrm{TM}}, \mathrm{EC}$ formed capillary-like structures after one day (Fig. 2E), however a collapse of these capillary-like structures was observed after five days (Fig. 2F). EC cultured on AG surfaces with or without gelatin augmentation formed aggregates and seemed to barely adhere to the gel surface (Fig. 2G-J). In some cases spheroids were observed (see arrows in Fig. 2I). Quantitative determination of cell adhesion was performed by counting cell nuclei under the different culture conditions. The number of cells on gelatin-coating increased from $130 \%$ to $340 \%$ within five days of culturing (Fig. 2B) when referred to the number of seeded cells. Cell numbers on different hydrogels were significantly reduced after one day and decreased further within five days (Fig. 2B). The addition of pro-adhesive (Relou et al., 1998) gelatin to the AG did not lead to an increase in the counted cell number. On Matrigel ${ }^{\mathrm{TM}}$, the adhesion was slightly increased as compared to the AG variants (Fig. 2B).

Cell vitality of EC was approved by live-dead staining. While almost all cells were vital on 2D-gelatin-coating, the relative amount of vital cells on Matrigel ${ }^{\mathrm{TM}}$ decreased from $92 \%$ to $72 \%$ within five days (Fig. 3A). The number of vital cells on the AG with (66\%) or without gelatin (67\%) was significantly reduced after one day as compared to gelatin-coating and Matrigel ${ }^{\mathrm{TM}}$ and even decreased after five days to $33 \%$ and $40 \%$, respectively (Fig. 3A). As illustrated in Fig. 3B, no cell death was induced through a 

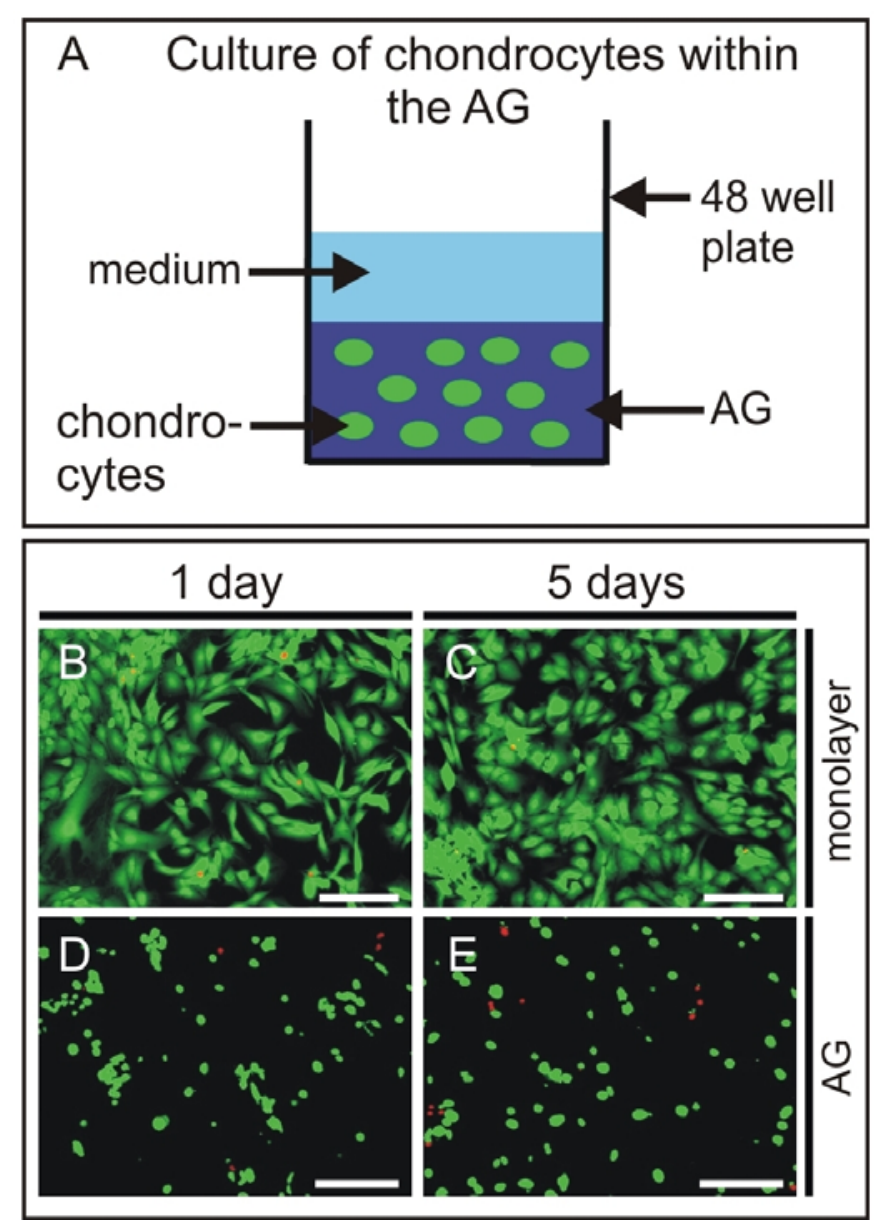

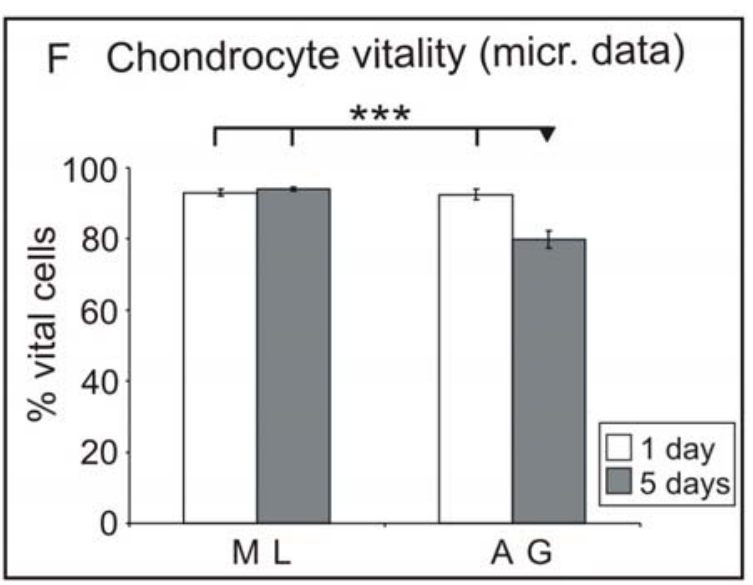

G Cytotoxicity (biochem. data)

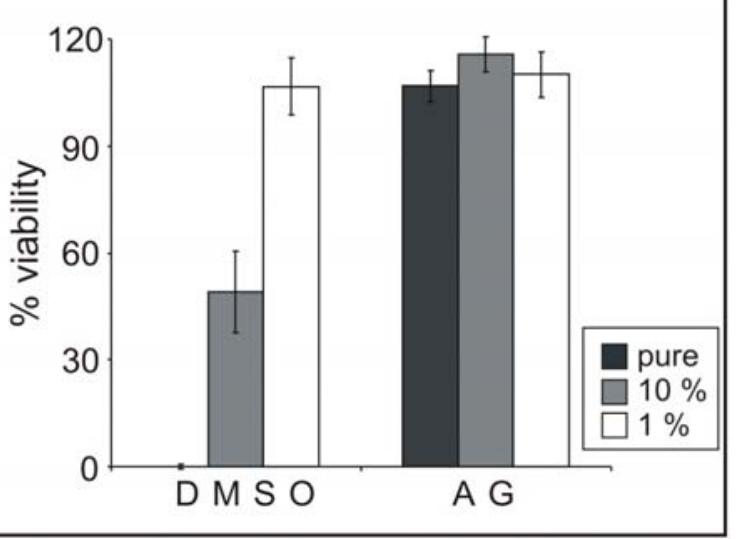

Figure 1: Chondrocyte vitality. Experimental layout (A). Live-dead staining of chondrocytes cultured in monolayers for one day (B) and five days (C) or within the AG for one day (D) and five days (E). Vital cells were stained with calcein (green) and dead cells with propidium iodide (red). In monolayer cultures, chondrocytes spread out and adhered to the bottom of the well plate while chondrocytes within the AG displayed a round morphology. Quantification of chondrocyte vitality $(F)$. Cytotoxicity assay $(G)$. In contrast to DMSO, medium supernatants of the AG showed no cytotoxic effect on chondrocytes. AG = albumin gel, biochem. = biochemical, DMSO = dimethyl sulphoxide, micr. $=$ microscopical, $\mathrm{ML}=$ monolayer; $* * *$ marks significance to arrowhead with $p<0.001$; scale bar $200 \mu \mathrm{m}$.

potential cytotoxic effect of the AG. In contrast to DMSO, neither medium supernatants of Matrigel ${ }^{\mathrm{TM}}$ nor medium supernatants of the $\mathrm{AG}$ and the $\mathrm{AG}+$ gelatin caused a decrease in cell viability (Fig. 3B), proposing the nonadhesive properties rather than a cytotoxic effect of the AG being responsible for the observed cell death. Furthermore, all vital cells were able to take up DiI-AcLDL (Fig. 3D, F, H, J) indicating the preservation of EC functionality under all culture conditions. Finally, the proliferation of EC was determined by incorporation of BrdU. The amount of proliferating cells was significantly increased on 2D-gelatin-coating (Fig. 4A and E) as compared to the different hydrogels (Fig. 4B, D, E), with Matrigel $^{\mathrm{TM}}$ exhibiting the lowest amount (Fig. 4C and E) of proliferating cells. In summary, it can be stated that the AG is not a permissive substrate for EC.

\section{EC migration and invasion}

Invasion of EC through Matrigel ${ }^{\mathrm{TM}}$ - and AG-coated Transwell filters was investigated to further substantiate the non-permissiveness of the AG for EC, whereas migration of EC through uncoated transwell filters was analyzed as internal control.
Rose Bengal stained EC (arrows) at the lower side of the Transwell filters are shown in Fig. 5C-J. Quantitative evaluation of the internal control revealed an increase in migrated cells after VEGF induction (Fig. 5B; 250 cells/ filter without VEGF, 1150 cells/filter with VEGF), confirming the principle ability of the utilized EC to respond to VEGF induction. Regarding the invasion of EC through the different hydrogel-coatings, we could show that 570 EC invaded through Matrigel $^{\mathrm{TM}}, 180 \mathrm{EC}$ through the $\mathrm{AG}$ and $300 \mathrm{EC}$ through the $\mathrm{AG}+$ gelatin (Fig. 5B). Although no significant difference was observed between the hydrogels due to high statistical variations, Matrigel $^{\mathrm{TM}}$ seemed to be more permissive for EC than the AG with or without gelatin.

\section{Impact of the AG on chick chorioallantoic membrane angiogenesis}

Blood vessels in the CAM exhibit an organized branching pattern. High order vessels branch into several lower order vessels, which then again branch into smaller vessels (DeFouw et al., 1989). Implantation of the AG and the $\mathrm{AG}+$ gelatin did not disturb this pattern (data not shown). In contrast, blood vessels seemed to exhibit less branching 


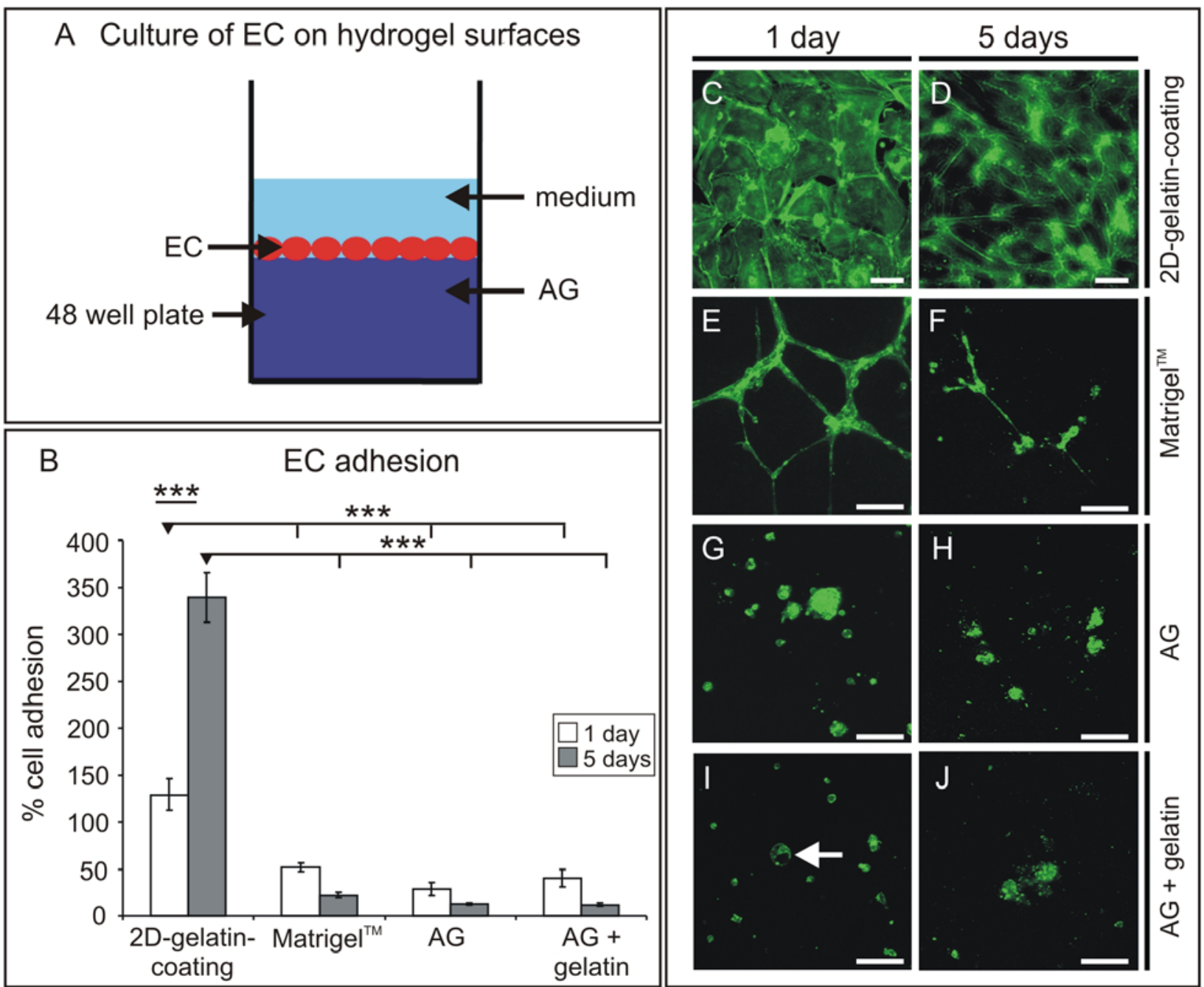

Figure 2: Endothelial cell adhesion. Experimental layout (A). Quantification of adherent EC (B). EC adhesion was reduced on hydrogels as compared to 2D-gelatin coating, with the AGs showing the lowest adhesive potential. Phalloidin staining of EC cultured on 2D-gelatin-coating $(C, D)$, $\operatorname{Matrigel}^{\mathrm{TM}}(\mathrm{E}, \mathrm{F})$, the $\mathrm{AG}(\mathrm{G}, \mathrm{H})$ and the $A G+$ gelatin (I, J). On gelatin-coating, EC showed a cobblestone-morphology and formed tubes when cultured on Matrigel $^{\mathrm{TM}}$, while aggregates were formed on AG surfaces. AG = albumin gel, EC = endothelial cells; *** marks significance to arrowhead with $p<0.001$; arrows mark spheroids; scale bars $100 \mu \mathrm{m}$ in C and D; $200 \mu \mathrm{m}$ in E - J.

points and changed direction abruptly when the $\mathrm{AG}+$ VEGF and the AG + chondrocytes were implanted onto the CAM (Fig. 6E and I). However, in the positive control (OptiMaix-3D ${ }^{\mathrm{TM}}$ ) only, blood vessels grew towards the implant in a spoked-wheel pattern (Fig. 6M). To further determine the angiogenic potential of the implants, the ratio of blood vessels growing in the direction of the implant (a) and centrifugally from the implant (b) was determined (Fig. 6C), assuming a positive correlation between the ratio $\mathrm{a} / \mathrm{b}$ and an angiogenic potential. For the $\mathrm{AG}$ and the $\mathrm{AG}+$ gelatin, the ratio did not differ from the ratio of the negative control (Fig. 6D). The ratio a/b was significantly increased in the positive control in comparison with all AG variants (Fig. 6D). Implantation of the $A G+V E G F$ led to a significant increase in the ratio, while the increase was not significant for the AG + chondrocytes (Fig. 6D). VEGF production in chondrocytes $\left(2 \times 10^{5}\right.$ cells $)$ cultured within the $\mathrm{AG}$ for five days in vitro varied between 1.2 and $10 \mathrm{ng}$ VEGF (Fig. 6B), indicating that the angiogenic potential of the $\mathrm{AG}+$ chondrocytes was slightly reduced as compared to the AG + VEGF (8 ng VEGF per gel).
Blood vessels in the implants were detected by means of HE-staining and SNA-binding, both of which allowed the detection of blood vessels in the chick CAM (data not shown). No blood vessels were observed in the AG and the $A G+$ gelatin (data not shown). Furthermore, despite the increased angiogenic potential, no blood vessels were found in the $\mathrm{AG}+\mathrm{VEGF}$ (Fig. $6 \mathrm{~F}$ and $\mathrm{G}$ ) and the $\mathrm{AG}+$ chondrocytes (Fig. 6J and K). When chondrocytes were co-implanted, cell nuclei (arrows) were visible within the AG (Fig. 6J and K). In contrast to the AGs, cell nuclei and blood vessels (arrowheads) were found in the positive control (Fig. 6N and O), excluding the possibility that blood vessels or cell nuclei were overlooked in the previous samples.

\section{Characterization of the AG with IVD chondrocytes in the backs of NOD/SCID mice}

IVD chondrocytes enclosed in the AG were implanted in the backs of NOD/SCID mice to analyze the ingrowth of blood vessels into the AG and the expression of cartilage specific markers by the IVD chondrocytes. Two weeks 

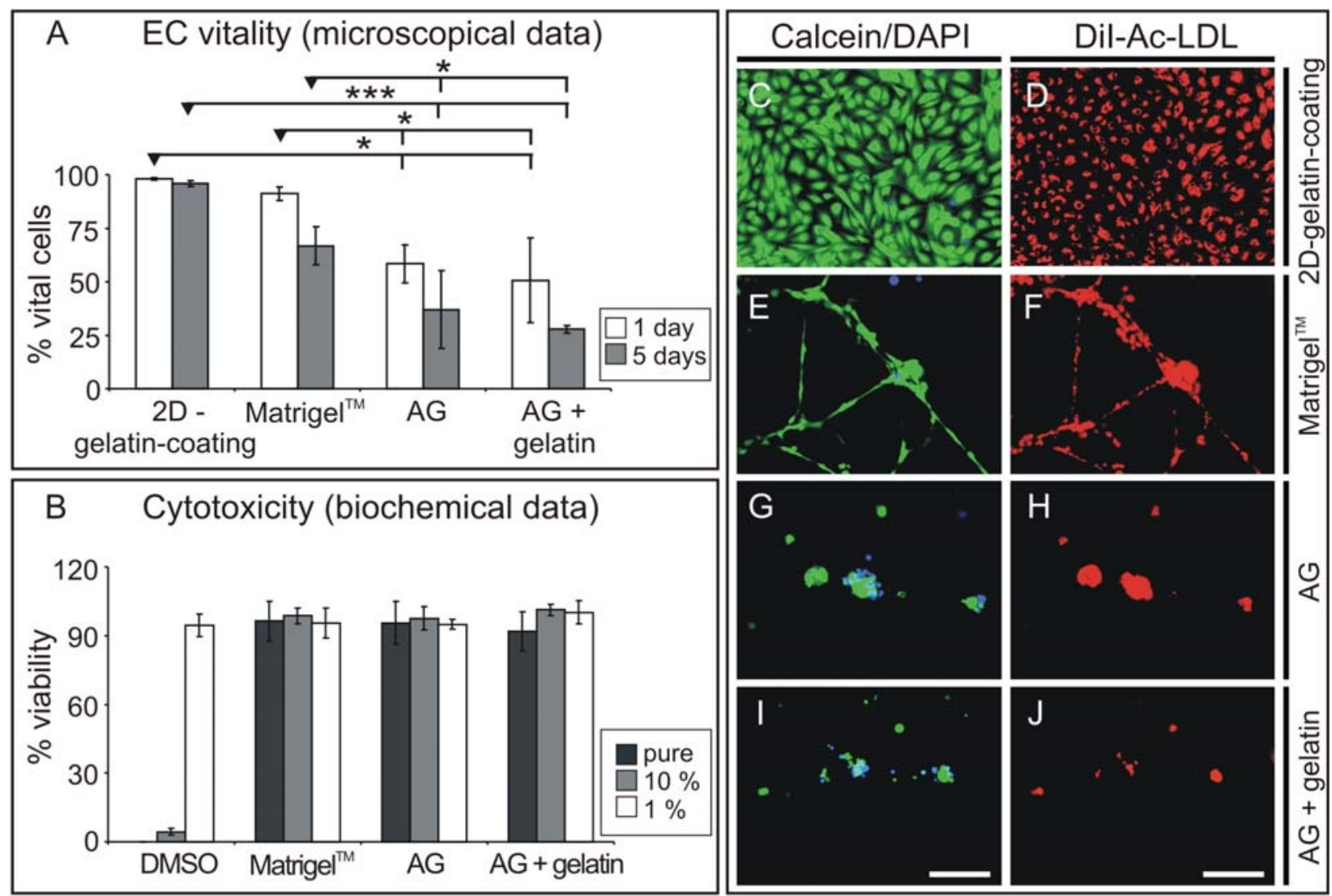

Figure 3: Endothelial cell vitality and functionality. Quantification of EC vitality (A). Vitality of EC decreased strongly on AG surfaces as compared to cells on gelatin-coating and Matrigel ${ }^{\mathrm{TM}}$. Cytotoxicity assay (B). In contrast to DMSO, medium supernatants of Matrigel $^{\mathrm{TM}}$, the AG and the AG supplemented gelatin showed no cytotoxic effect on EC. Live-dead staining of EC on 2D-gelatin-coating (C), Matrigel ${ }^{\mathrm{TM}}(\mathrm{E})$, the AG (G) and the AG + gelatin (I). Vital cells were stained with calcein (green) and dead cells with DAPI (blue). The number of dead cells increased on the $\mathrm{AG}$ and the $\mathrm{AG}+$ gelatin as compared to gelatin-coating and Matrigel ${ }^{\mathrm{TM}}$. Uptake of DiI-Ac-LDL of EC cultured on 2D gelatin-coating (D), Matrigel ${ }^{\mathrm{TM}}(\mathrm{F})$, the $\mathrm{AG}(\mathrm{H})$ and the $\mathrm{AG}+$ gelatin $(\mathrm{J})$. All still viable cells were able to incorporate DiI-Ac-LDL. AG = albumin gel, DAPI = 4',6-diamidino-2-phenylindole, DiI-Ac-LDL = acetylated low-density lipoprotein labeled with 1,1'-dioctadecyl-3,3,3',3'-tetramethylindocarbocyanine perchlorate, EC = endothelial cells; **** marks significance to arrowhead with $p<0.05 / 0.001$; scale bars $200 \mu \mathrm{m}$.
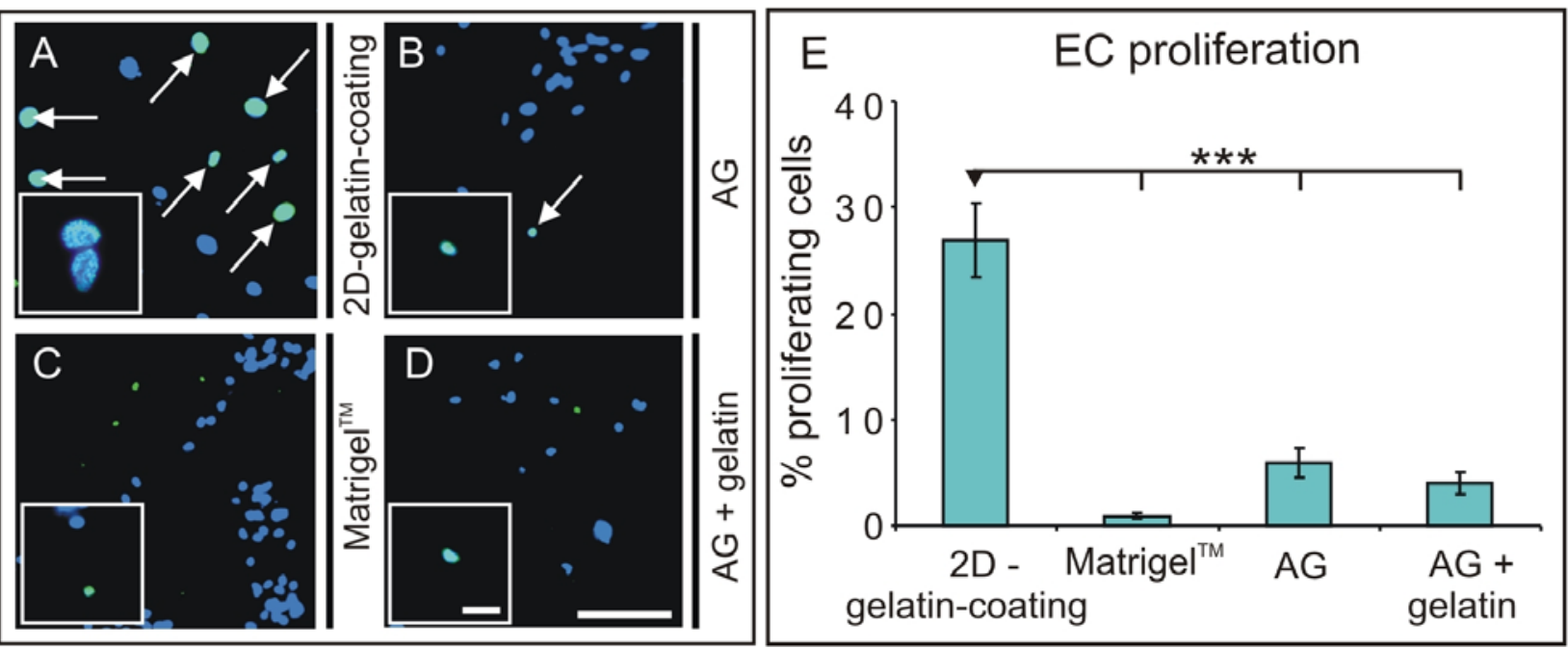

Figure 4: Endothelial cell proliferation. Staining of cell nuclei with DAPI (blue) and proliferating cells with BrdU (light green) on 2D-gelatin-coating (A), Matrigel ${ }^{\mathrm{TM}}(\mathrm{B})$, the AG (C) and the AG supplemented with gelatin (D). The highest number of proliferating cells was observed on gelatin-coating. Quantification of EC proliferation (E). Proliferation was strongly increased on 2D-gelatin coating as compared to the hydrogels. $\mathrm{AG}=$ albumin gel, $\mathrm{BrdU}=$ 5-bromo-2'-deoxyuridine, $\mathrm{EC}=$ endothelial cells; *** marks significance to arrowhead with $p<0.001$; arrows mark proliferating cells; scale bar $100 \mu \mathrm{m}$, scale bar in insert $30 \mu \mathrm{m}$. 

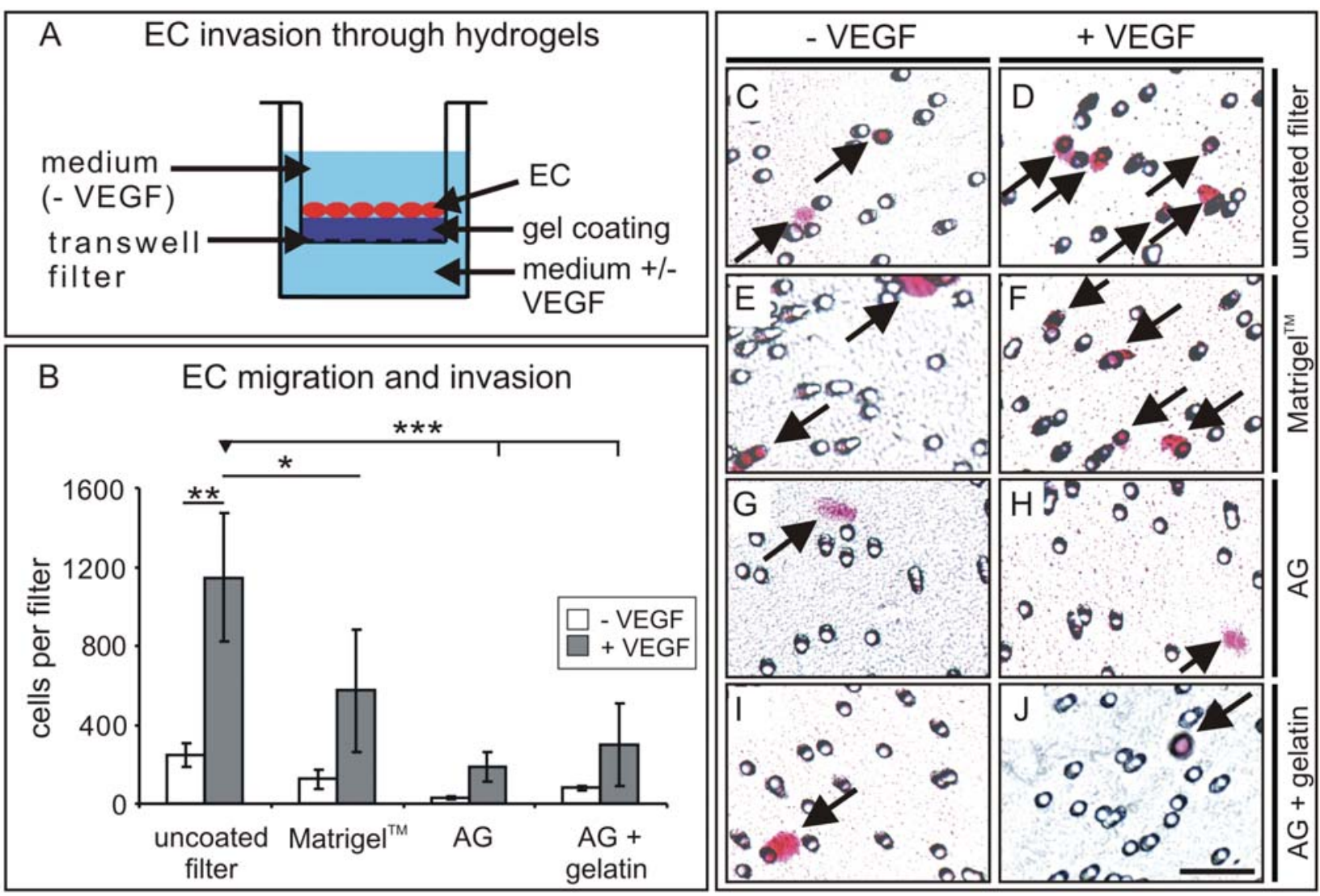

Figure 5: Endothelial cell migration and invasion. Experimental layout (A). Quantification of transmigrating EC (B). VEGF-induced migration was increased as compared to non-stimulated migration. Matrigel ${ }^{\mathrm{TM}}$ was more permissive for $\mathrm{EC}$ than the $\mathrm{AG}$ and the $\mathrm{AG}+$ gelatin. Rose Bengal stained $\mathrm{EC}$ at the lower side of uncoated transwell filters $(C, D)$, Matrigel ${ }^{\mathrm{TM}}$-coated filters $(\mathrm{E}, \mathrm{F}), \mathrm{AG}$-coated filters $(\mathrm{G}, \mathrm{H})$ and $\mathrm{AG}+$ gelatin-coated filters (I, $\mathrm{J}) . \mathrm{AG}=$ albumin gel, $\mathrm{EC}=$ endothelial cells, $\mathrm{VEGF}=$ vascular endothelial growth factor; $* / * * / * * *$ marks significance to arrowhead with $p<0.05 / 0.01 / 0.001$; arrows mark Rose Bengal stained EC; scale bar $25 \mu \mathrm{m}$.

after implantation, blood vessels were evident in the surrounding subcutaneous tissue, but not in the implant (see arrows Fig. 7A insert). These results were confirmed immunohistochemically. The AG (Fig. 7C, *) was devoid of vWF-positive blood vessels, while blood vessels were detected in the surrounding tissue. In contrast, HE-staining did not reveal blood vessels in the surrounding tissue (Fig. 7B). Gene expression of the chondrocyte-specific markers aggrecan, collagen type II and collagen type I was analyzed by real-time-PCR after explantation of the AG. As monolayer expansion before implantation into the patient within the AG is obligatory for clinical application, monolayer cultures were analyzed as control. A significant increase in gene expression was observed for all three markers compared with monolayer control (Fig. 7E), thereby coincidentally approving vitality of the IVD chondrocytes. For aggrecan, expression was also analyzed on the protein level. Aggrecan was found at the periphery of the AG, but to a lesser extent in the centre of the AG or in the surrounding tissue (Fig. 7D).

\section{Discussion}

We hypothesized whether a currently developed hydrogel based on cross-linked albumin would suppress adverse angiogenesis while supporting chondrocytes, thus underscoring its utility as a structural component for implantation of chondrocytes to treat traumatic and degenerative skeletal disorders. We were able to show that $\mathrm{EC}$ were hardly able to adhere onto the $\mathrm{AG}$ and that EC vitality was strongly reduced. In contrast to culturing on 2D-gelatin, almost no proliferating EC were found on the AG.

The AG remains soft after polymerization which could be one reason for the decreased adhesive potential of EC on the AG. Many cell types are able to respond to the stiffness of their substrate leading to strongly reduced cell adhesion when cultured on soft substrates (Discher et al., 2005). At the molecular level, the reduction of substrate stiffness leads to a decrease in focal-adhesion associated proteins in HUVEC (Deroanne et al., 2001). Furthermore, it has been shown that anchorage-dependent EC undergo cell death when exposed to non-adhesive conditions (Chen et al., 1997; Flusberg et al., 2001; Meredith et al., 1993; Polte et al., 2007), which is consistent with our observations. Cell proliferation is typically restricted to matrix-attached cells (Ben-Ze'ev et al., 1980; Folkman and Moscona, 1978), a fact which explains the reduced EC proliferation rates on the AG.

For other applications, the stiffness of the AG could be modulated by increasing the concentrations of maleimide-groups and SH-groups, possibly leading to an increased EC adhesion. However, we did not investigate 

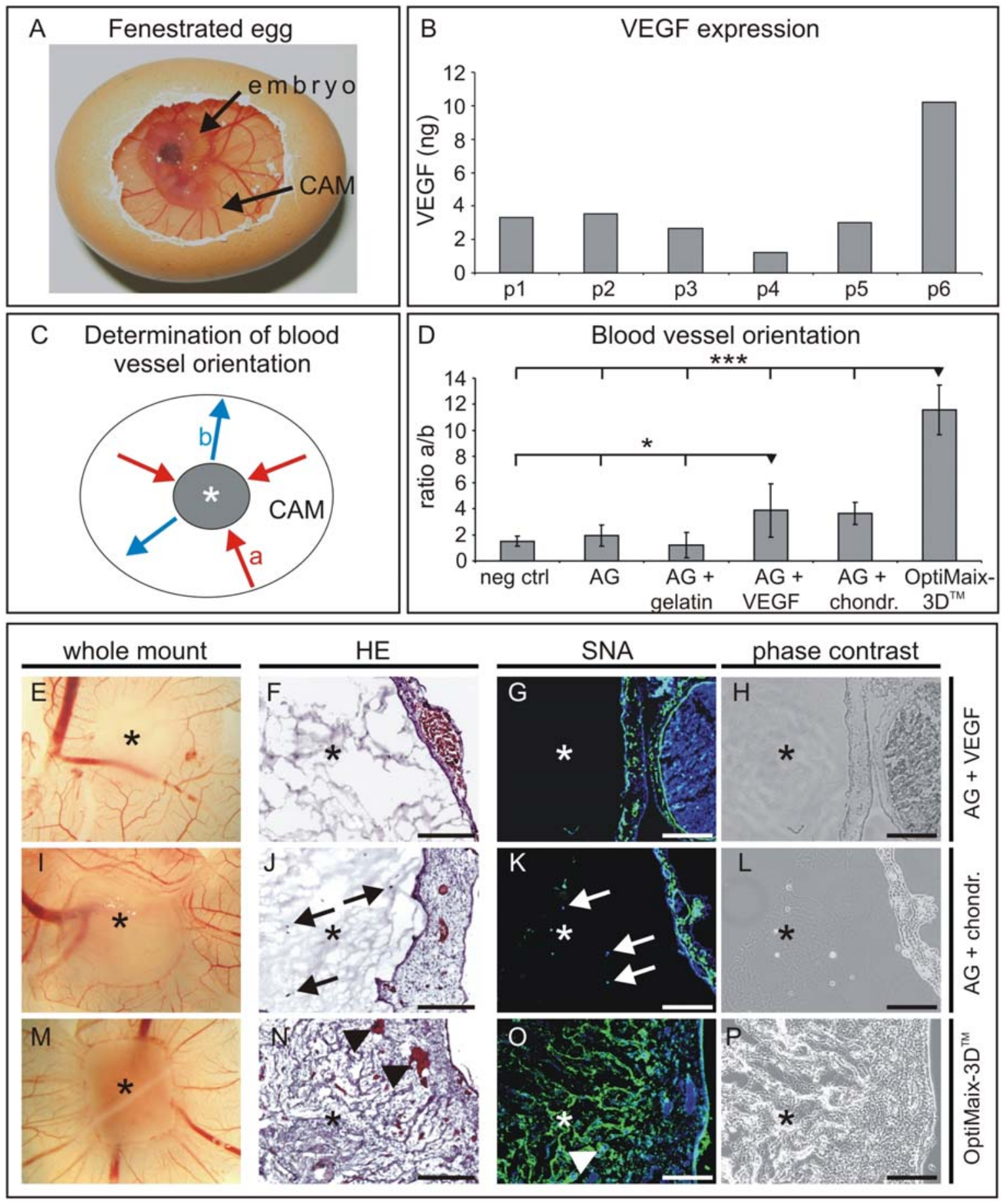

Figure 6: CAM Assay. Fenestrated egg with chorioallantoic membrane onto which probes were implanted (A). VEGF expression of articular chondrocytes (B). Within five days of culture in the AG, $2 \times 10^{5}$ chondrocytes from different patients produced between 1.2 and $10 \mathrm{ng}$ VEGF. Scheme for the determination of blood vessel orientation (C). Blood vessels growing in the direction of the implant (a) and blood vessels growing centrifugally from the implant (b) were counted to determine the ratio $\mathrm{a} / \mathrm{b}$. Blood vessel orientation in the CAM depicted as ratio $\mathrm{a} / \mathrm{b}(\mathrm{D})$. The ratio $\mathrm{a} / \mathrm{b}$ was slightly increased for the $\mathrm{AG}+\mathrm{VEGF}$ and the $\mathrm{AG}+$ chondrocytes and strongly increased for the positive control OptiMaix-3 $\mathrm{D}^{\mathrm{TM}}$ as compared to the negative control, the $\mathrm{AG}$ and the $\mathrm{AG}+$ gelatin. Explanted $\mathrm{CAMs}$ with the AG + VEGF (E), the AG + chondrocytes (I) and the positive control OptiMaix-3D $\mathrm{D}^{\mathrm{TM}}(\mathrm{M})$. In the positive control only, blood vessels grew towards the implant in a spoked-wheel pattern. HE-staining of the CAM with the AG + VEGF (F), the AG + chondrocytes (J) and the positive control (N). EC-specific SNA-staining and corresponding phase contrast images of the CAM with the AG + VEGF $(\mathrm{G}, \mathrm{H})$, the $\mathrm{AG}+$ chondrocytes $(\mathrm{K}, \mathrm{L})$ and the positive control $(\mathrm{O}, \mathrm{P})$. Blood vessels were only found in the positive control. $\mathrm{AG}=$ albumin gel, $\mathrm{CAM}=$ chorioallantoic membrane, chondr. $=$ chondrocytes, $\operatorname{ctrl}=$ control, $\mathrm{HE}=$ hematoxylin eosin, impl. $=$ implant, $\mathrm{p}=$ patient, $\mathrm{SNA}=$ sambucus nigra agglutinin, VEGF $=$ vascular endothelial growth factor; */*** marks significance to arrowhead with $p<0.05 / 0.001$ (D); * marks the implant (C, E-P), arrows mark cell nuclei, arrow heads mark blood vessels in the implant (N, O); scale bars $200 \mu \mathrm{m}$. 

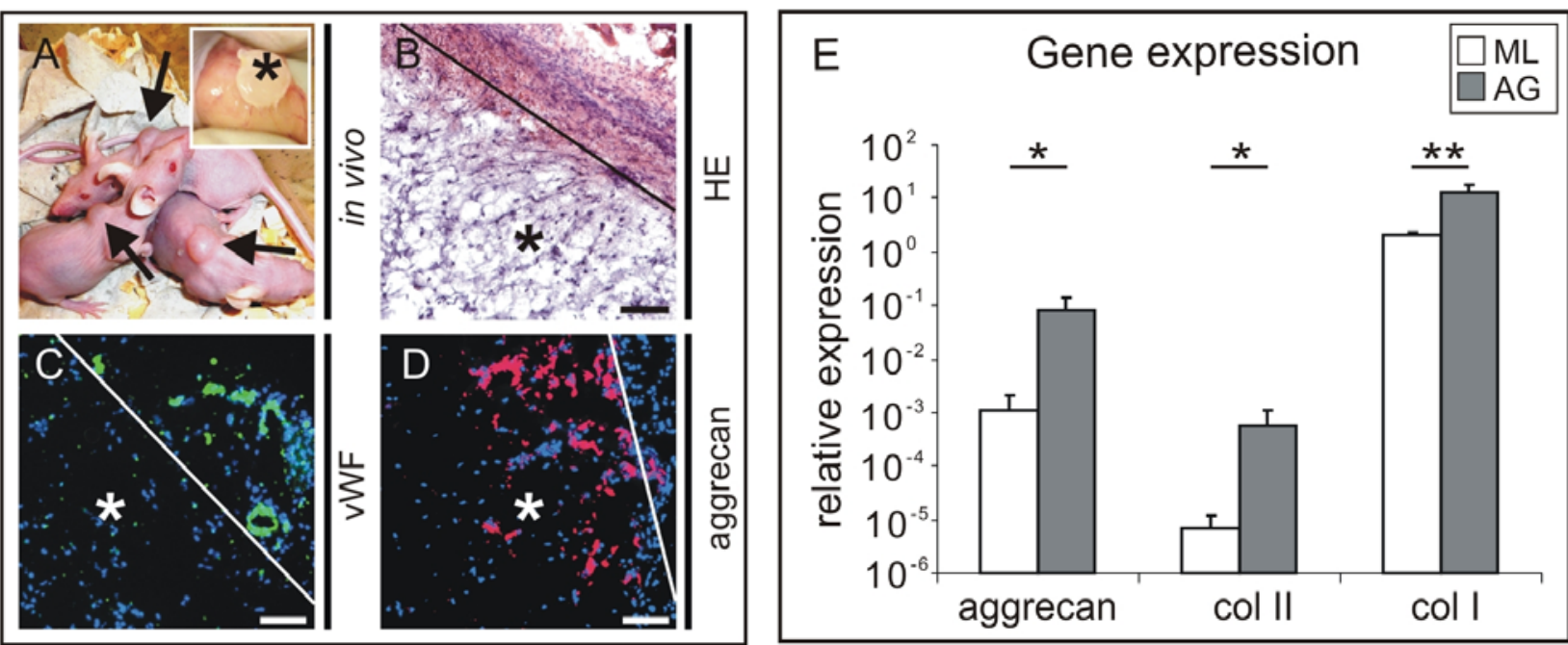

Figure 7: Implantation of the albumin gel in NOD/SCID mice. NOD/SCID mice with the AG + IVD chondrocytes subcutaneously implanted and an explanted AG two weeks post implantation (insert) (A). HE-staining of the implant and the surrounding tissue (B). No blood vessels were found in the implant and the surrounding tissue. Immunohistochemical staining of vWF (C). The implant was devoid of blood vessels, while vWF-positive blood vessels were found in the surrounding tissue. Immunohistochemical staining of aggrecan (D). Aggrecan was found in the implant but not in the surrounding tissue. Gene expression analysis of the IVD chondrocytes after explantation. The results are depicted as relative expression in comparison to GAPDH. Gene expression of aggrecan, collagen type II and type I were increased as compared to monolayer controls. AG = albumin gel, col = collagen, GAPDH = glyceraldehyde-3-phosphate dehydrogenase, $\mathrm{HE}=$ hematoxylin eosin, $\mathrm{ML}=$ monolayer, NOD/SCID $=$ non-obese diabetic/severe combined immune deficiency, $\mathrm{vWF}=$ von Willebrand factor; $* / * *$ marks significance with $p<0.05 /$ $0.01(\mathrm{E})$; $^{*}$ marks the implant (A insert, B-D), arrows mark the site of implantation; lines in B, C and D mark the border between implant and the surrounding tissue; scale bars $100 \mu \mathrm{m}$.

this aspect in the current study as our main goal was to investigate the impact of an already approved hydrogel, which has been optimized for the regeneration of articular cartilage and the IVD, on angiogenesis.

During angiogenesis, EC emigrate from destabilized blood vessels to form new sprouts (Carmeliet, 2003; Soker et al., 2000) representing an important step in angiogenesis. For this reason, we wanted to investigate the ability of EC to transmigrate through the AG. The Matrigel ${ }^{\mathrm{TM}}$ chemoinvasion assay, which had been employed to analyze the invasive potential of EC and tumour cells through basement membranes (Albini, 1998), was used for analysis. As the change between the unstimulated control and VEGF induction appeared to be comparable under all conditions, VEGF seemed to be able to diffuse through both the Matrigel $^{\mathrm{TM}}$ - and the AG-coating in a similar fashion. However, compared to Matrigel ${ }^{\mathrm{TM}}$, EC were hardly able to penetrate the AG. Presumably, the non-adhesive properties of the AG were causal for the inability of EC to invade through the AG.

The results of the chemoinvasion assay gave a first hint that the AG could possibly represent a barrier for blood vessels in vivo. To confirm this assumption we analyzed the ingrowth of blood vessels into the AG by performing two additional in vivo assays: implantation of AG, a) onto the chick CAM (Dreesmann et al., 2007; Norrby, 2006; Ribatti et al., 2001) and, b) into the subcutaneous space of NOD/SCID mice (Stoop et al., 2007). No blood vessel formation within the pure $\mathrm{AG}$ was observed in in ovo CAM assays. To exclude that EC ingrowth might be dependent on chemoattraction (Ferrara et al., 2003), VEGF additionally was implemented into the gel, as VEGF is synthesized by chondrocytes in osteoarthritis (Enomoto et al., 2003; Honorati et al., 2007; Murata et al., 2008). Neither recombinant VEGF nor encapsulated chondrocytes (which also produced significant amounts of VEGF) within the AG were able to induce endothelial infiltration. One possible limitation of the CAM assay is the pre-existence of blood vessels on the day of implantation hampering the distinction between these vessels and neovascularisation (Ribatti et al., 1996; Ribatti et al., 2001). To overcome this limitation we also analyzed the CAM without implants as negative control to obtain a baseline value for preexisting blood vessels. Another limitation is the fact, that the CAM is an embryonic tissue exhibiting exaggerating angiogenesis. However, in this case, we consider this fact to be advantageous. As the AG is able to be a barrier for blood vessels in this highly active tissue, it also promises to inhibit the ingrowth of blood vessels in degenerating cartilage. The AG including IVD chondrocytes implanted in the backs of NOD/SCID mice remained devoid of blood vessels after two weeks post implantation. Since VEGF was found in herniated discs, most likely expressed by IVD chondrocytes (Tolonen et al., 1997), we assume that the IVD chondrocytes utilized in our experiments also expressed VEGF. Taking all points in account, the AG displayed a barrier function for angiogenic EC in two different in vivo experiments. 
The strict non-permissiveness of the AG for EC questioned whether chondrocytes to be co-transplanted in a clinical setting might deteriorate in the AG. Our data substantiated chondrocyte vitality within the $A G$ for extended periods. In contrast to EC, chondrocytes are not anchorage-dependent (Archer et al., 1982; Benya and Shaffer, 1982). In native articular cartilage, chondrocytes display a round morphology without cell-cell contacts (Archer and Francis-West, 2003), very similar to what we observed in our approach. In addition, the state of chondrocyte differentiation appeared to follow cell-type specific gene expression. After two weeks of implantation in NOD/SCID mice, the IVD chondrocytes within the AG expressed the cartilage-specific markers aggrecan, collagen type I and collagen type II in a similar fashion as in vivo (Gottschalk et al., 2001). These data are consistent with earlier reports indicating that the ECM production in chondrocytes is increased under non-adhesive conditions (Archer et al., 1982). Consequently, the non-adhesive properties of the AG might even be beneficial for chondrocyte metabolic activity.

We were able to show by two control experiments that articular and IVD chondrocytes were vital within the AG and expressed cartilage specific markers. By contrast, the AG was non-permissive for EC as shown in five different in vitro and in vivo assays. In this study we identified further features of the AG, namely barrier properties for blood vessels. As angiogenesis is involved in the progression of degenerative cartilage diseases, this feature could contribute to the regeneration of degenerated cartilage tissue after the implantation of autologous chondrocytes.

\section{Acknowledgement}

We are grateful to Dr. Y. Baumer and E. Tetling for scientific and technical assistance and to Maureen Meyer for correcting the manuscript as a native speaker. This work was supported by the BMBF 0313755.

\section{References}

Albini A (1998) Tumor and endothelial cell invasion of basement membranes. The matrigel chemoinvasion assay as a tool for dissecting molecular mechanisms. Pathol Oncol Res 4: 230-241.

Anderson D, Risbud M, Shapiro I, Vaccaro A, Albert T (2005) Cell-based therapy for disc repair. Spine J 5: 297S-303S.

Archer CW, Francis-West P (2003) The chondrocyte. Int J Biochem Cell Biol 35: 401-404.

Archer CW, Rooney P, Wolpert L (1982) Cell shape and cartilage differentiation of early chick limb bud cells in culture. Cell Differ 11:245-251.

Ashraf S, Walsh DA (2008) Angiogenesis in osteoarthritis. Curr Opin Rheumatol, 20: 573-580.

Ballara SC, Miotla JM, Paleolog EM (1999) New vessels, new approaches: angiogenesis as a therapeutic target in musculoskeletal disorders. Int J Exp Pathol 80: 235-250.
Ben-Ze'ev A, Farmer SR, Penman S (1980) Protein synthesis requires cell-surface contact while nuclear events respond to cell shape in anchorage-dependent fibroblasts. Cell 21: 365-372.

Benya PD, Shaffer JD (1982) Dedifferentiated chondrocytes reexpress the differentiated collagen phenotype when cultured in agarose gels. Cell 30: 215224.

Bonnet CS, Walsh DA (2005) Osteoarthritis, angiogenesis and inflammation. Rheumatology (Oxford) 44: 7-16.

Boyd L, Carter A (2006) Injectable biomaterials and vertebral endplate treatment for repair and regeneration of the intervertebral disc. Eur Spine J 15 Suppl 3: S414421.

Carmeliet P (2003) Angiogenesis in health and disease. Nat Med 9: 653-660.

Chan B, Leong K (2008) Scaffolding in tissue engineering: general approaches and tissue-specific considerations. Eur Spine J 17 Suppl 4: 467-479.

Chen CS, Mrksich M, Huang S, Whitesides GM, Ingber DE (1997) Geometric control of cell life and death. Science 276: $1425-1428$.

DeFouw DO, Rizzo VJ, Steinfeld R, Feinberg RN (1989) Mapping of the microcirculation in the chick chorioallantoic membrane during normal angiogenesis. Microvasc Res 38: 136-147.

Deroanne CF, Lapiere CM, Nusgens BV (2001) In vitro tubulogenesis of endothelial cells by relaxation of the coupling extracellular matrix-cytoskeleton. Cardiovasc Res 49: 647-658.

Discher DE, Janmey P, Wang YL (2005) Tissue cells feel and respond to the stiffness of their substrate. Science 310: 1139-1143.

Dreesmann L, Ahlers M, Schlosshauer B (2007) The pro-angiogenic characteristics of a cross-linked gelatin matrix. Biomaterials 28: 5536-5543.

Enomoto H, Inoki I, Komiya K, Shiomi T, Ikeda E, Obata K, Matsumoto H, Toyama Y, Okada Y (2003) Vascular endothelial growth factor isoforms and their receptors are expressed in human osteoarthritic cartilage. Am J Pathol 162: 171-181.

Ferrara N, Gerber HP, LeCouter J (2003) The biology of VEGF and its receptors. Nat Med 9: 669-676.

Flusberg DA, Numaguchi Y, Ingber DE (2001) Cooperative control of Akt phosphorylation, bcl-2 expression, and apoptosis by cytoskeletal microfilaments and microtubules in capillary endothelial cells. Mol Biol Cell 12: 3087-3094.

Folkman J, Moscona A (1978) Role of cell shape in growth control. Nature 273: 345-349.

Gottschalk D, Fehn M, Patt S, Saeger W, Kirchner T, Aigner T (2001) Matrix gene expression analysis and cellular phenotyping in chordoma reveals focal differentiation pattern of neoplastic cells mimicking nucleus pulposus development. Am J Pathol 158: 15711578 .

Haro H, Kato T, Komori H, Osada M, Shinomiya K (2002) Vascular endothelial growth factor(VEGF)-induced angiogenesis in herniated disc resorption. J Orthop Res 20: $409-415$. 
Hengstler JG, Bolm-Audorff U, Faldum A, Janssen K, Reifenrath M, Gotte W, Jung D, Mayer-Popken O, Fuchs J, Gebhard S, Bienfait HG, Schlink K, Dietrich C, Faust D, Epe B, Oesch F (2003) Occupational exposure to heavy metals: DNA damage induction and DNA repair inhibition prove co-exposures to cadmium, cobalt and lead as more dangerous than hitherto expected. Carcinogenesis 24: 6373.

Honorati MC, Cattini L, Facchini A (2007) VEGF production by osteoarthritic chondrocytes cultured in micromass and stimulated by IL-17 and TNF-alpha. Connect Tissue Res 48: 239-245.

Huber M, Trattnig S, Lintner F (2000) Anatomy, biochemistry, and physiology of articular cartilage. Invest Radiol 35: 573-580.

Hunziker EB (1999) Articular cartilage repair: are the intrinsic biological constraints undermining this process insuperable? Osteoarthritis Cartilage 7: 15-28.

Johnson W, Evans H, Menage J, Eisenstein S, El Haj A, Roberts S (2001) Immunohistochemical detection of Schwann cells in innervated and vascularized human intervertebral discs. Spine 26: 2550-2557.

Meredith JE, Jr., Fazeli B, Schwartz MA (1993) The extracellular matrix as a cell survival factor. Mol Biol Cell 4: 953-961.

Murata M, Yudoh K, Masuko K (2008) The potential role of vascular endothelial growth factor (VEGF) in cartilage: how the angiogenic factor could be involved in the pathogenesis of osteoarthritis? Osteoarthritis Cartilage 16: $279-286$.

Norrby K (2006) In vivo models of angiogenesis. J Cell Mol Med, 10: 588-612.

O'Brien J, Wilson I, Orton T, Pognan F (2000) Investigation of the Alamar Blue (resazurin) fluorescent dye for the assessment of mammalian cell cytotoxicity. Eur J Biochem 267: 5421-5426.

Paesold G, Nerlich AG, Boos N (2007) Biological treatment strategies for disc degeneration: potentials and shortcomings. Eur Spine J 16: 447-468.

Polte TR, Shen M, Karavitis J, Montoya M, Pendse J, Xia S, Mazur E, Ingber DE (2007) Nanostructured magnetizable materials that switch cells between life and death. Biomaterials 28: 2783-2790.

Relou IA, Damen CA, van der Schaft DW, Groenewegen G, Griffioen AW (1998) Effect of culture conditions on endothelial cell growth and responsiveness. Tissue Cell 30: 525-530.

Ribatti D, Vacca A, Roncali L, Dammacco F (1996) The chick embryo chorioallantoic membrane as a model for in vivo research on angiogenesis. Int J Dev Biol 40: 1189-1197.

Ribatti D, Nico B, Vacca A, Roncali L, Burri PH, Djonov V (2001) Chorioallantoic membrane capillary bed: a useful target for studying angiogenesis and antiangiogenesis in vivo. Anat Rec 264: 317-324.

Roughley P (2004) Biology of intervertebral disc aging and degeneration: involvement of the extracellular matrix. Spine 29: 2691-2699.

Soker S, Machado M, Atala A (2000) Systems for therapeutic angiogenesis in tissue engineering. World $\mathrm{J}$ Urol 18: 10-18.
Sontjens SH, Nettles DL, Carnahan MA, Setton LA, Grinstaff MW (2006) Biodendrimer-based hydrogel scaffolds for cartilage tissue repair. Biomacromolecules 7: 310-316.

Stoop R, Albrecht D, Gaissmaier C, Fritz J, Felka T, Rudert M, Aicher WK (2007) Comparison of marker gene expression in chondrocytes from patients receiving autologous chondrocyte transplantation versus osteoarthritis patients. Arthritis Res Ther 9: R60.

Tolonen J, Gronblad M, Virri J, Seitsalo S, Rytomaa T, Karaharju EO (1997) Platelet-derived growth factor and vascular endothelial growth factor expression in disc herniation tissue: and immunohistochemical study. Eur Spine J 6: 63-69.

Vinatier C, Mrugala D, Jorgensen C, Guicheux J, Noel D (2009) Cartilage engineering: a crucial combination of cells, biomaterials and biofactors. Trends Biotechnol 27: 307-314.

Voyta JC, Via DP, Butterfield CE, Zetter BR (1984) Identification and isolation of endothelial cells based on their increased uptake of acetylated-low density lipoprotein. J Cell Biol 99: 2034-2040.

\section{Discussion with Reviewers}

Reviewer I: For clinical application it would be interesting to know how stable the albumin-based hydrogel is under in vivo conditions. Is it biodegradable and if so, is it replaced by the proliferating chondrocytes in the gel or by granulation tissue of low quality over time?

Authors: The albumin gel is already in clinical application for repair of tibial plateau defects in the knee and talar dome defects in the ankle. No side effects were seen. In SCID mouse experiments, complete resorption of the biomaterial took place within 12 weeks. Since SCID mice do not display an inflammatory response, the observed resorption has to be based on non-inflammatory degradation.

Reviewer I: What is the ideal ratio between the gel phase and the incorporated chondrocytes for the generation of articular cartilage and IVD constructs?

Authors: Currently, we favour a cell dose that resembles closely the natural cell density in joint cartilage. In sheep experiments with successful healing of nucleotomized intervertebral discs, the cell dose was also equivalent to the natural density.

Reviewer II: What makes albumin a unique system for this application?

Authors: Albumin hydrogels have already been introduced by several groups for the tissue engineering applications (D'Urso et al., 1995; Kim et al., 2008; Leach and Schmidt, 2005; Snyders et al., 2007). However, the main rationale for the utilization of albumin for this application was due to practical considerations. Medical prescription formulations of human serum albumin have already drug status facilitating the approval for our hydrogel on albumin basis for clinical application, which we propose should be 
considered when designing a new biomaterial for tissue engineering.

Reviewer II: "Would inflammation not be a better target than angiogenesis? As one is a precursor for the other?" Authors: Of course, angiogenesis and inflammation are involved in the degeneration of cartilage. However, angiogenesis can occur without inflammation. Angiogenesis plays an important role in embryogenesis and also in tumour growth (Carmeliet, 2003; text reference) displaying two examples where angiogenesis is not connected to inflammatory processes. In osteoarthritis the ingrowth of bony outgrowths is related to angiogenesis (Ballara et al., 1999; text reference) similar to osteochondral bone formation (Dai and Rabie, 2007) resembling another process where angiogenesis takes places without inflammation. Furthermore, the innervation of articular cartilage and the intervertebral disc is related to angiogenesis (Ashraf and Walsh, 2008; Paesold et al., 2007; text references) but not to inflammation. Therefore, we consider angiogenesis per se to be an essential factor in the progression of degenerative cartilage diseases, which must not necessarily be associated with inflammatory processes.

Reviewer II: A biomimetic approach typically involves the use of an ECM component that is derived from the matrix of the targeted tissue. In this case albumin is usedwhich is present if at all in minimal quantity in the disc. The reviewer would like to see a response to this comment. Authors: The utilized albumin gel with supplemented hyaluronic acid represents a matrix in which chondrocytes are highly vital and metabolically active. Within this artificial matrix chondrocytes are able to produce their own EC, making the use of an ECM component as a basis of the hydrogel unnecessary. However, we mimicked aspects of the microenvironment of native cartilage by three other conditions. The viscosity of the albumin gel resembled native conditions and the transplanted cell number was in accordance with the cell density found in articular cartilage or intervertebral discs. Furthermore, hyaluronic acid, as a component of native cartilage, was added to the albumin gel. Albumin only serves as a neutral element to provide for the polymer backbone and has been chosen because of its already established properties as a pharmaceutical and because neither the intact molecule nor its degradation product are known to influence chondrocytes metabolically.

\section{Additional References}

D’Urso EM, Jean-Francois J, Doillon CJ, Fortier G (1995) Poly(ethylene glycol)-serum albumin hydrogel as matrix for enzyme immobilization: biomedical applications. Artif Cells Blood Substit Immobil Biotechnol 23: $587-595$.

Dai J, Rabie AB (2007) VEGF: an essential mediator of both angiogenesis and endochondral ossification. J Dent Res 86: 937-950.

Kim DN, Lee W, Koh WG (2008) Micropatterning of proteins on the surface of three-dimensional poly(ethylene glycol) hydrogel microstructures. Anal Chim Acta 609:5965.

Leach JB, Schmidt CE (2005) Characterization of protein release from photocrosslinkable hyaluronic acidpolyethylene glycol hydrogel tissue engineering scaffolds. Biomaterials 26: 125-135.

Snyders R, Shingel KI, Zabeida O, Roberge C, Faure MP, Martinu L, Klemberg-Sapieha JE (2007) Mechanical and microstructural properties of hybrid poly(ethylene glycol)-soy protein hydrogels for wound dressing applications. J Biomed Mater Res A 83: 88-97. 